\title{
Museu de Arte Contemporânea de Serralves: Projectos com Escolas
}

\author{
Moema Martins Rebouças \\ Investigadora da Capes e do i2ADS ${ }^{1}$
}

\section{Resumo}

A Fundação Serralves é uma instituição cultural de âmbito internacional que possui um Museu de Arte Contemporânea com um Serviço Educativo (SE) responsável pela organização de programas para o público em geral e especialmente para as escolas. Este artigo apresenta parte de uma investigação sobre o Projetos com Escolas proposto pelo SE no ano 2012/2013 e envolve desde a estrutura e organização deste projeto anual aos protagonistas e as ações interinstitucionais geradas por ele. Como percurso metodológico utiliza materiais publicados pelo Serviço Educativo e conversas com os protagonistas dessas ações (Serviço Educativo da FS) e profissionais da escola envolvidos no projeto. Para fundamentação recorre aos princípios da semiótica francesa e/ou discursiva.

Palavras chaves: museu e escola, análise de discurso, arte contemporânea.

\begin{abstract}
Serralves Foundation (FS in Portuguese) is a cultural institution of International range that owns a Museum of Contemporary Art with an Educational Service (SE in Portuguese) responsible for organizing programs for the general public, and specially for schools. This paper presents part of an investigation about the Projects with Schools proposed by the SE in 2012/2013, and concerns from the structure and organization of this annual project, to its chief actors and the inter-institutional actions it generates. Its methodology uses material published by the SE and talks held with the main actors of such actions (Educational Service of FS) and with the professionals from schools involved in the project. As a theoretical basis it uses the principles of French, or discursive semiotics.
\end{abstract}

Key-words: museum and school, discourse analysis, contemporary art.

\footnotetext{
${ }^{1}$ Professora da UFES e pesquisa realizada com bolsa Capes junto ao Núcleo de Educação Artística do Instituto de Investigação em Arte, Design e Sociedade da FBAUP.
} 
A Fundação Serralves (FS) é uma instituição cultural de âmbito internacional criada em 1989 na cidade do Porto em Portugal. Oriunda de um contexto em que a sociedade portuguesa distancia-se tanto do período autoritário como do pós-revolucionário ( ANICO, 2008) $)^{2}$, e de um duplo movimento de consolidação da democracia e de adesão à Comunidade Econômica Européia foi resultado de um investimento do governo que aliado a importantes grupos financeiros investe na reconstrução de sua imagem a partir de ações no campo das artes representativas dessa nova postura.

A Fundação Serralves (FS) tem como missão sensibilizar o público para a arte contemporânea em ações propostas no Museu de Arte Contemporânea (MAC) e nelas integrar o ambiente e a educação utilizando o parque em que está instalada que é patrimônio natural. Projetado pelo arquiteto Álvaro Siza $^{3}$ de modo a articular os elementos arquitetônicos à Casa Serralves e ao parque, a edificação do Museu constitui-se por si como patrimônio de interesse arquitetônico

No espaço da internet da FS está publicado que ${ }^{4}$ as atividades propostas que envolvem o parque e o museu são desenvolvidas em torno de 5 eixos estratégicos que atuam interligados, são eles: Artes, Ambiente, Indústria criativa, reflexão e educação. Entre os seus objetivos está o da constituição de um acervo de arte contemporânea portuguesa e internacional, a programação de exposições temporárias, o desenvolvimento de projetos com jovens artistas e a organização de programas educativos, estando estes sob a responsabilidade de um setor denominado Serviço Educativo (SE) .

Condizente com a proposta pluridisciplinar, o Serviço Educativo tem como objetivo

[...] sensibilizar e motivar os diferentes públicos para as temáticas da arte, da arquitectura, do ambiente e da cidadania, integrando momentos de formação, de partilha de conhecimentos, emoções e valores, que estimulam uma aproximação crítica e criativa à cultura contemporânea, potenciando a fruição de um espaço com características singulares (Fundação Serralves. Disponivel: <http://www.serralves.pt/>. Acesso em: 25 ago. 2012).

Para essa sensibilização, conta com uma ambiência da natureza desenhada ali em percursos que integram e põem em relação as edificações da Casa Serralves e do Museu de Arte Contemporânea. Desse modo, arte e natureza são parte de uma mesma totalidade a ser explorada pelo Serviço Educativo em programações diversificadas e transversais voltadas para a formação de públicos.

\footnotetext{
${ }^{2}$ Ver Anico (2008) as mudanças ocorridas após a revolução e a ênfase inicial do governo na definição da estrutura política e econômica do país, ficando a cultura e os museus em uma posição secundária.

${ }^{3}$ Álvaro Siza destaca-se como um dos mais importantes arquitetos portugueses com reconhecimento e alcance internacional tanto por sua atuação como professor ( formação de futuros arquitetos), como em áreas de habitação social à complexos residenciais, equipamentos culturais e sociais, arte pública e recuperação urbanística.

${ }^{4}$ http://www.serralves.pt/pt/fundacao/a-fundacao/eixos-estrategicos/.Acesso em: 4 de julho.2013.
} 
Entre as ações propostas pelo setor educativo as quais envolvem a comunidade escolar há uma que nos interessa e, por esse motivo, foi escolhida para a investigação que este artigo relata: trata-se do Projectos ${ }^{5}$ com Escolas.

O objetivo da investigação foi o de conhecer o Projectos com Escolas do ano 2012/2013 para compreender como ele é estruturado, quem são os seus protagonistas (destinadores e destinatários) e como eles participam desse processo; como são propostas e criadas as parcerias e/ou práticas colaborativas interinstitucionais; como e quais ações interinstitucionais são geradas por esse Projeto anual.

O percurso metodológico adotado consistiu-se na análise dos materiais publicados pelo Serviço Educativo, especialmente o relacionado ao recorte temporal da investigação, e envolveu, ainda, encontros e conversas com os protagonistas dessas ações, que são desde os destinadores/enunciadores (do Serviço Educativo da FS), até os profissionais da escola envolvidos no projeto (duas professoras) e os trabalhos realizados pelos alunos expostos no Museu de Arte Contemporânea de Serralves.

Para a fundamentação das análises, utilizamos os princípios da semiótica francesa e/ou discursiva, que considera o discurso como uma instância de mediação e lugar das manifestações do saber e do não-saber que caracterizam as performances discursivas.

Sobre o discurso, Greimas (1976, p.5) esclarece tratar-se de uma problemática pautada não no sujeito como produtor do discurso, mas na performance que ele realiza. Nela, o plano do exercício individual da linguagem não pode ser considerado como fixo, pois se relaciona com as práticas discursivas que ocorrem nas interações, e é no plano social que elas se modificam e se transformam. Sendo assim, o sujeito do discurso, ao realizar a sua performance, torna-se um outro, ao interagir com algo ou alguém; é, portanto, um sujeito em construção permanente. Como a manifestação dessas performances discursivas está presente nos documentos disponibilizados e enunciados pelo Serviço Educativo da Fundação Serralves (programas e materiais impressos e publicados no sítio da FS), nas conversas com os enunciadores e com as professoras a quem estes discursos são destinados $^{6}$, é com esse referencial que elas serão analisadas. Portanto, o que será analisado é o dito e o modo de dizer, ou seja, como os protagonistas desse projeto nos fazem saber de suas participações nele.

\footnotetext{
${ }^{5}$ O Projectos com Escolas é a denominação dada ao projeto anual proposto pelo SE de Serralves e que envolve várias ações, utilizarei nessa investigação o plural como está designado por Victorino (2008).

${ }^{6} \mathrm{O}$ recorte temporal em que foi realizada essa investigação( de maio a outubro), não nos possibilitou a inclusão de outros integrantes da escola que participam desse Projeto, como os alunos, demais profissionais e pais.
} 
Acreditamos que, pela análise discursiva, será possível conhecer e compreender como uma instituição museológica articula, em suas ações, relações interinstitucionais, integrando arte e sociedade; além disso, poderemos investigar a que concepções de educação da arte se vincula essa instituição e como se posicionam os protagonistas dessas ações.

\section{Uma aproximação entre arte e cultura.}

Essa investigação considera os discursos e as práticas artísticas e educacionais dessas instituições (museu e escola) como enunciações sociais que assumem as marcas dos contextos em que se encontram, ou seja, não são práticas isoladas e nem homogêneas. Toma como hipótese a ideia de que, a depender desse contexto e das concepções de arte inscritas nessas ações, são mobilizados modos diferenciados de aproximação com as comunidades que as integram e, especificamente, com a escolar.

As diferentes concepções de cultura e arte têm sido abordadas por teóricos como Argan (1993), Darras (2009), Barbosa (2009). Tais teóricos apontam a prevalência, na tradição ocidental, de fundamentos de uma concepção humanística que promove os valores das elites ocidentais. Darras (2009) categoriza e propõe uma tipologia dessa concepção de cultura e arte e a divide em três categorias. Na primeira delas, considera que os espaços culturais e sociais são contínuos, ou seja, como não há separação, são considerados os valores de mercado e de consumo tais como os de raridade, novidade, universalidade, ou ainda os valores da cultura, que as dividem em uma concepção edificante e aristocrática proposta em hierarquias classificatórias tais como de autenticidade, singularidade, originalidade, entre outras. Nessa mesma categoria, apresenta uma outra subdivisão que, embora se fundamente nos mesmos princípios humanistas, rejeita as suas dimensões hierárquicas. Nela, os valores são equânimes, e nunca uma cultura é superior a outra.

Em outro bloco de sua tipologia, apresenta os sistemas divididos da cultura por três modos de interação. O primeiro deles pertence aos sistemas autopoiéticos e se caracteriza pela recusa das relações sociais, voltando-se para os estudos da criação, da obra, do artista e da produção de sua identidade. Reconhece as variantes multiculturais, entretanto considera que cada grupo se constitui numa dinâmica insular.

No segundo modo de interação, estão os sistemas interdependentes que, tais como os dialéticos, requerem que as relações entre natureza e cultura, inteligível e sensível, arte e cultura, entre outras, acentuem uma ou outra em operações de contradição, negação e de totalidade. E, por fim, os sistemas dialógicos, que, por sua autonomia e independência, são complementares a seu meio e a seus antagonistas. Essa categoria se pauta na defesa de 
que a cultura organiza o mundo e a si mesma, e a arte e a indústria cultural organizam o mundo cultural, organizando-se internamente.

A tipologia de Darras (2009) evidencia como diferentes concepções de arte e cultura coexistem e recortam o mundo cultural e, nesse atuar, advogamos que edificam e modalizam os discursos e as práticas artísticas e educacionais, inclusive as promovidas pelos setores educativos dos museus.

Argan (1993) atribui à crítica da arte a atuação na mediação entre a arte e o público, orientando os seus interesses e escolhas. E, como o acesso à produção e à cultura artísticas é responsabilidade dos museus (ou espaços com essa mesma destinação de guarda, conservação, catalogação, entre outras ações), são eles que oferecem material para atuação da crítica e para a manutenção da tutela sobre o "conhecimento da arte". Mas também são os museus que podem, a partir de seus projetos, contrapor a esta concepção de arte como bem econômico e destinado a uma elite, uma outra que a compreenda como fator educativo de que toda a sociedade poderá usufruir e se apropriar.

\section{O serviço educativo}

Despertar o prazer de aprender, de realizar e criar são objetivos comuns a todos os projectos desenvolvidos pelo Serviço Educativo de Serralves em parceria com as escolas, no pressuposto de que no prazer está implícito esforço, trabalho, empenho e sentido de responsabilidade (LEITE \& VICTORINO, 2008:15).

A tríade composta por aprendizagem, realização e criação que as educadoras do Serviço Educativo de Serralves apontam como fundamentação para todos os projetos desenvolvidos com escolas tem origem tanto numa pedagogia renovada que se pauta na experiência, tal como propunha Dewey (1968), quanto na educação visual tendo como base os estudos de Munari (1982) e, em processos de investigação-ação como proposto por Barbier (1985).

A pedagogia renovada ganha espaço em Portugal com a luta pela democratização do ensino que tem como base as reformas que vinham ocorrendo desde a primeira república que tinham como objetivo a descentralização da instrução primária, estendendo-a aos meios rurais e à valorização dos professores.

Para os pedagogos adeptos ao movimento da Escola Nova, democratizar a escola é torná-la um espaço democrático em que as crianças possam crescer como sujeitos de seu próprio desenvolvimento e assim tornarem-se autônomas. Portanto, é com essa perspectiva 
que entre outros investimentos na educação, tendo como pauta a democratização da escola que foi realizado o acordo em Portugal chamado Luso-Sueco (1972-1982). Tal acordo consistia em ações programáticas de preparação e formação de professores tais como a proposta do Seminário Experimental para Formação de Formadores e nele as oficinas de sensibilização ao Trabalho de Projecto ${ }^{7}$. A metodologia de Trabalho de Projecto consistiu em um dos focos de preparação dos professores para uma mudança de abordagem pedagógica no ensino formal ou escolar, e são os princípios dela que fundamentam as ações dos projetos educativos destinados as escolas propostos em Serralves.

Para que se conheça um pouco os motivos que justificam a escolha de uma metodologia que se origina no ensino formal e fundamenta uma prática do ensino não escolar $^{8}$, é importante esclarecer que a assessora e consultora do Serviço Educativo de Serralves, Elvira Leite possui ampla experiência como professora nas escolas da cidade do Porto ${ }^{9}$, e também atuou na formação de professores em Portugal e em outros países, além de ter participado em ações de estudo e investigação promovidas pelo intercâmbio entre os dois países participantes do acordo. Portanto, pode-se afirmar que é pela via do ensino escolar que o ensino não escolar proposto por Serralves se constituiu, ou seja pelos saberes e experiências de seus propositores/enunciadores.

Para a consultora da FS, Elvira Leite ${ }^{10}$, o Trabalho de Projetos no museu e no âmbito do Projectos com Escolas possui características próprias que o distingue de outros processos de ensino, pois ao integrar tanto os métodos qualitativos para a ação como os de aprender fazendo transformam a ideia em ato, e nesse fazer possibilitam aos educandos a aquisição de saberes de várias vertentes tanto ao nível dos conceitos, como das atitudes e dos valores. Está então na escolha do Serviço Educativo de Serralves pelo Trabalho de Projetos para nortear os Projectos com Escolas a possibilidade de instituir ali um espaço interativo em que as instituições educativas e museológicas possam estabelecer um diálogo aberto às múltiplas vozes, conforme apontam a coordenadora e a consultora desse setor

\section{II.1. Como se estrutura o Projeto com as Escolas}

\footnotetext{
${ }^{7}$ Cf. Sobre o acordo luso-sueco e o Trabalho com Projetos consultar Leite, E;Malpique, M e Santos, M. (2001) e (1990).

${ }^{8}$ Utilizo nesse estudo o termo não escolar para designar a educação fora do eixo escolar como é a educação em museus.

${ }^{9}$ A Prof. Elvira Leite também é artista e foi professora do Ensino Secundário na area de Artes, orientou seminarios e possui publicações sobre criatividade, espaço pedagógico e trabalho de projeto.

${ }^{10}$ Consultar LEITE \& VICTORINO, 2008, p.21.
} 
$\mathrm{Na}$ FS o Projectos com Escolas 2012/2013 teve como temática Lugares Imaginários: Utopia e Transição ${ }^{11}$ e envolveu em torno de 49 instituições, entre escolas, associações e organizações educativas e cerca de 114 professores. As escolas estão localizadas em diferentes distritos, como os de Aveiro, Porto, Viana do Castelo, Vila Nova de Gaia e Vila Real. Direcionando-o para faixas etárias que abrangem crianças da pré-escola a jovens e adolescentes do ensino secundário, as enunciadoras do projeto dividiram a temática dirigindo às crianças a primeira parte do tema os Lugares Imaginários e aos jovens e adolescentes a segunda Utopia e Transição. Ao justificar a divisão lançam uma provocação:

Será que o facto de procurar no imaginário lugares inexistentes alimenta o exercício de ver, ler, questionar, observar, dialogar, participar na construção do amanhã? Esses lugares serão brincalhões, excêntricos, habitados nos sonhos, percepcionados com os olhos fechados para mais intensamente se sentir o que existe e não se vê - odores, sensações táteis, temperaturas, aragens, ventanias, chuva, cheiros, sonoridades. Mas também podem ser idealizados a partir do que se aprende sobre Ambiente e Ciência Viva ${ }^{12}$.

$\mathrm{Na}$ leitura e transcrição desse trecho, me distancio da escrita e, aceitando a provocação feita, penso: relacionar a arte ao imaginário é instituir não um lugar, mas todos os lugares, não uma possibilidade, mas todas as possibilidades. Assim a arte pode ser, ao mesmo tempo tão próxima da vida e da natureza/cultura que se apresenta integrada no parque de Serralves e em tantos lugares por que passamos habitualmente.

A arte que o texto expõe quer estabelecer um outro modo de relação possível com o entorno, por meio das sensações sensoriais olfativas, táteis, auditivas entre outras, e que não necessitam somente da visão. Se pensarmos nas ordens sensórias para a fruição de obras de uma estética clássica era a visão a mais exigida pois era ela que conduzia e instaurava o nosso olhar na obra ${ }^{13}$, a arte contemporânea exigirá, para que se interaja com ela, a convocação de outras ordens sensoriais e de outros comportamentos, não somente a observação.

A proposta então, coerente com o que Serralves expõe, prepara esse enunciatário para o encontro com a arte contemporânea.

A apresentação da segunda parte é iniciada pela frase: "Talvez mais dirigida a jovens que frequentam o ensino secundário Utopia Transição.

\footnotetext{
${ }^{11}$ Consultar http://1213.projetoescolas.serralves.pt/pt/ acesso em 05/08/2013.

${ }_{12}$ Consultar Ib.dib p:1.

${ }^{13}$ Um exemplo é o espaço perspectivo assumido pela pintura naturalista renascentista que somente é modificado no modernismo com o espaço planar.
} 
O pode-ser instaura e demarca a abertura que a própria apresentação do tema do projeto contem, ou seja, é uma possibilidade, não um dever-fazer imposto e que separa um do outro, os que podem e os que não podem. Constitui assim um argumento, uma possibilidade e uma saída da programação.

O programático é pautado pelo fazer-fazer, faz parte do contexto escolar e também das instituições museológicas e se manifesta na organização dos espaços, na distribuição dos tempos e, na escola, tanto no currículo como nos planos de aula dos professores. No museu, a programação se faz presente na organização das visitas (horário, limite de crianças por visita), e até na conduta de um monitor que faz crer ao visitante que o único modo de interação possível naquele espaço se dá pela intermediação dos aparelhos, tais como os auditivos, que conduzem a visita conforme um tempo determinado e/ou ainda indicam o que deve ser visto. É claro que o visitante pode, em seu fazer interpretativo, recusar essa estratégia ou mesmo aceitá-la parcialmente, ou seja, não se submeter ao aparelho e realizar a visita em seu próprio tempo. Contudo, pode-se afirmar que é o regime de interação pautado na programação das ações entre os sujeitos e entre eles e os objetos que estrutura e organiza a escola e o museu.

Voltando à análise do texto de apresentação do tema, sua sequência recupera esse todo de sentido a partir do qual a temática é proposta, como destaco a seguir:

Etimologicamente, utopia significa 'não-lugar'. Não é de facto um lugar físico
e real, mas um lugar de imaginação, um lugar imaginário, esse lugar onde se
projetam os sonhos que fazem avançar ou não a Humanidade.

Há na proposta apresentada uma opção por quatro conceitos que, ao mesmo tempo em que ampliam para várias direções os projetos que poderão ser propostos pelos professores e alunos nas escolas, podem envolvê-los numa totalidade de ações propositivas e criativas geradoras de trabalhos.

Desde a apresentação da temática do Projeto anual, destaca-se a presença da liberdade de ações para as etapas seguinte, ou a recusa ao programático (fazer-fazer). Não há nenhum enunciado prescritivo neste texto de apresentação que direcione o modo, ou os modos de desenvolvimento dos projetos nas escolas. Na conversa com a consultora Elvira Leite, ela nos explica que quando assumidos pelos professores nas escolas, cada qual direciona e propõe o seu próprio projeto conforme os acordos estabelecidos entre os sujeitos que lá estão (crianças e adolescentes). Então, nessa perspectiva o projeto proposto por Serralves funciona como se fossem três projetos. O inicial é o projeto proposto por Serralves 
que possui uma temática e os apoios para s professores e crianças e adolescentes, depois os professores a partir dessa temática propõem a seus alunos os projetos que eles têm, e os alunos vão fazer um projeto que é o deles na sequência desses dois projetos. Portanto, mesmo havendo um tema, quando o projeto chega nas escolas eles podem ter outros temas e cada escola possui a sua autonomia.

Para contemplar essa sequencialidade de ações que cada projeto gera, o SE de Serralves, no que corresponde à primeira etapa, organiza e propõe um cronograma que envolve: a apresentação da temática e inscrições (2/10/2012); seminário para educadores e professores (01/ 2013); ações de formação e de oficinas para educadores e formadores (de 01 a 03/2013); oficinas temáticas para alunos do pré-escolar ao secundário (de 01 a 03/2013); visitas ao parque e ao museu (de 01 a 03/2013); entrega de trabalhos produzidos nas escolas (04/2013) e exposição final em Serralves (05 a 09/2013).

Os seminários, as oficinas e as visitas constituem ações de apoio para as segunda e terceira etapas, que serão realizadas nas escolas. Para esse apoio, a coordenadora Elizabete Alves nos explica que a equipe do SE de Serralves é composta por um coordenador e dois assistentes para cada área, ou seja, um para as artes e outro para o meio ambiente, sendo que a marcação de visitas e toda a produção das ações de todos os projetos educativos ${ }^{14}$ estão sob a responsabilidade dessa equipe. Para que consigam atender a tantos projetos ela nos explica que:

"A nossa equipe são os investigadores, monitores, artistas plásticos e alguns professores que têm algum tempo livre e colaboram conosco. Como se vai criando um relacionamento continuado, no fundo vamos criando uma cultura comum. É um esforço comum, porque vai se criando algo intermitente ao longo dos anos, mesmo com as mudanças na coordenação do S.E. Mas o que nós acreditamos que é essencial de fazer são os encontros mensais com a equipe toda,[...] no início pensamos em oficinas com algumas pessoas e depois começamos a convidar os monitores a partilhar.[...] juntamos artes e meio ambiente. Alguma ou outra experiência de ter uma oficina com um artista e um biólogo".

Para se ter uma ideia do envolvimento dessa equipe no projeto de $2012 / 2013$, foram ofertadas para os alunos do pré-escolar ao secundário 18 oficinas ${ }^{15} \mathrm{com}$ concepções e orientações de 13 diferentes artistas/orientadores, no período de janeiro a março de 2013. Para os educadores e professores, foram ofertadas 4 oficinas com a participação de 5 artistas/orientadores e os seminários, que contaram com a participação de artistas, cientistas

\footnotetext{
${ }^{14}$ A Fundação Serralves possui uma diversidade de projetos educativos, além do que apresentamos aqui, direcionados para o público em geral, como as visitas guiadas, a família em Serralves, Férias em Serralves entre outros.

${ }^{15}$ Consultar programas das oficinas http://1213.projetoescolas.serralves.pt/fotos/editor2/programadeoficinas.pdf, acesso em 6/08/2013.
} 
e outros profissionais convidados para possibilitar o desenvolvimento de estudos que envolvam os conceitos da temática do projeto anual.

Sobre esse processo e como essas ações se articulam, Elvira nos explica que inicialmente é realizado um seminário que conta com a participação dos professores que querem se integrar ao projeto anual, depois são propostos encontros com especialistas das áreas que o projeto abrange. A presença do professor é imprescindível pois aquele é o momento do debate e das propostas a serem realizadas nos momentos subsequentes.

A partir desses dados, constata-se que o elo entre Serralves e as escolas se dá pela participação do professor. É o professor que se inscreve no projeto, e em todas as ações que o envolvem, dos seminários às oficinas, conforme podemos verificar nas fichas de inscrição que devem ser preenchidas por eles e entregues a Serralves (anteriormente, em nota de rodapé, já disponibilizamos tais fichas). Para que os alunos possam participar das oficinas, é necessária a presença do professor ou de outro profissional da escola designado por ele ou pela própria escola. É também o professor ${ }^{16}$ que se responsabiliza pela segunda e terceira etapas do projeto e as inclui em seu planejamento escolar com a turma. É ele, portanto, que, entre as turmas que possui, escolhe aquela que participará do projeto. Podese afirmar que o Projectos com as Escolas de Serralves é um contrato de confiança firmado entre o professor e Serralves, e que, para se constituir como um projeto interinstitucional entre escolas e Serralves, é antes um projeto pessoal/profissional estabelecido entre os professores e Serralves.

Assim, esse profissional, para participar do projeto, tem de atender a sua carga horária semanal na escola e, para estar presente nos seminários e oficinas direcionados a ele, tem de encontrar horários alternativos aos de sua docência. Para garantir essa participação do professor, o SE de Serralves oferece as oficinas integradas ao projeto, de janeiro a março.

Acrescentam-se aos fatores apontados acima as condições de trabalho afetadas pelas mudanças no sistema educativo português, para reiterar que essa participação se dá mais pelo envolvimento e profissionalismo dos docentes do que pelas facilidades que o contexto escolar Ihes oferece.

\footnotetext{
${ }^{16}$ As informações que não fundamentam essa análise foram obtidas em conversas com duas professoras participantes do projeto anual de Serralves que concordaram em participar desta investigação.
} 
Sobre essa participação dos professores, Elvira reconhece a responsabilidade do professor e acrescenta ainda a dos alunos e a da família como elos importantes que explicam tanto a longevidade desse projeto como o seu alcance.

O fato de ter sido professora e o modo como conduziu a sua vida profissional faz com que a interlocução estabelecida entre o SE de Serralves, mediada por Elvira, e os professores se estabeleça entre iguais, de professor para professor. Há o entendimento do que é o tempo na escola e de como o professor concilia e administra o seu tempo de professor com o que vive fora da escola, além de outros papéis que assume, como na sua família e no estabelecimento de uma vida social e cultural e que abrange, entre outras ações, a ida a museus.

\section{II.2. Seminário/oficinas/corpo/natureza sensibilidades a explorar.}

As coisas acontecem pelas mãos das pessoas que acreditam profundamente, ponto final.

(Elizabete Alves)

Após a apresentação do tema em outubro de 2012 , os seminários, as visitas e a oficinas, assim como a entrega de trabalhos produzidos nas escolas e a organização da exposição final constituem ações de apoio do SE de Serralves direcionados para o Projetos com Escolas.

$\mathrm{Na}$ estrutura do cronograma, as três ações foram ofertadas de modo concomitante a partir de janeiro de 2013 , tendo as oficinas e as visitas se estendido até março.

Se os seminários envolvem os conceitos da temática do projeto anual para possibilitar o estudo e aprofundamento dela, as oficinas condizentes com a investigaçãoação que fundamenta a metodologia de Trabalho de Projectos caracterizam-se pela abertura ou liberdade de escolha para o professor e os alunos, pois, além da oferta em horários e datas diferenciadas, possibilitam a adequação aos projetos realizados nas escolas e contemplam várias linguagens, tais como a corporal, a plástica, a musical, a verbal e a escrita. No material disponibilizado por Serralves, Elvira afirma que, com tal abrangência, elas "[..] poderão ser integradas, assim como trabalhadas as dimensões social, ecológica, política, cultural, artística"17.

17 Consultar http://1213.projetoescolas.serralves.pt/fotos/editor2/programadeoficinas.pdf, acesso em 6/08/2013. 
Das quatro oficinas propostas para os professores, duas delas caracterizam-se por proporem uma relação mais subjetiva com o próprio corpo. Têm como título "Os segredos do universo estão gravados no nosso corpo" e "O ofício de tantos horizontes e imagens". A primeira delas, em sua ementa, possui duas citações: a de um artista e a de um escritor e com elas estabelece relações interdiscursivas e intertextuais. Do livro Memória de um corpo, do artista Alberto Carneiro, cita-se: "Sei apenas que o meu corpo é o corpo árvore, o corpo rocha, o corpo rio, o corpo terra transfigurado em obra". E de Milman Dan, o seguinte trecho: "Tudo o que precisamos de saber está aí dentro de nós. Os segredos do universo estão gravados no nosso corpo". Na ementa, os orientadores convidam os participantes a "[...] viajar dentro e fora de si próprios." Isso nos leva a concluir que o objeto modal que possibilita a realização desse fazer proposto pelos enunciadores está no próprio corpo do participante/professor, a partir da sensação de seu sentir-se em movimento. Enunciam também que o modo de figurativizar o diálogo intertextual corpo/terra, corpo/memórias será por meio de desenhos e em escritas criativas. Assim, toda a temática da oficina é a do corpo/sentido como materialidade a ser explorada.

Outros diálogos se presentificam nessa ação, como o estabelecido com o artista Alberto Carneiro, que foi um dos expositores do Museu de Arte Contemporânea no período que abrangeu o projeto em 2013. Ele é também um dos artistas a ocupar o parque de Serralves com a obra Ser Árvore e ser Arte. Portanto, a oficina, ao trazer a voz do artista, dialoga com a sua obra, que é parte da coleção, e convida o participante/professor a interagir com ela e a viver essa experiência a partir de seu próprio corpo.

As outras duas oficinas possuem uma proposta diferenciada das anteriores, com o título: "Intervenções (não) utópicas" e "Manifestação ASUL", a primeira problematiza o espaço escolar e propõe modos de intervenção para a transformação dele em um lugar utópico. Para isso, convoca os participantes a realizarem essa intervenção "com criatividade e senso crítico". A segunda oficina, de modo mais abrangente, inclui em sua convocatória para a ação as manifestações públicas desde a antiguidade e propõe que "[...] tarjas, movimentos, panfletos cânticos, cartazes, ruídos e palavras criarão um corpo manifestante em direção a algum Norte". A temática da primeira está em torno da ocupação espacial da escola; a da segunda lida com a ocupação do espaço público ${ }^{18}$.

Nessa perspectiva, o espaço pode ser ocupado, apreendido e ressignificado. Como componente de relações pedagógicas nas salas de aula, pode tanto ser ocupado como nas

\footnotetext{
${ }^{18}$ A discussão do espaço como componente pedagógico foi proposta desde 1983 numa publicação da Coleção Ser Professor como componente de um seminário de formação do acordo luso-sueco. Consultar Carneiro, A, Leite, E, Malpique, M. (1983). Os estudos sobre o espaço também fazem parte da abordagem semiótica que o considera como significante. Consultar Greimas, A,Kristeva,C.L,Bremond et al. (1980).
} 
aulas tradicionais, quanto pode ser alterado e, nesse fazer, aproximar e romper as posições de quem lidera, ou ainda ser reorganizado conforme as situações de quem o utiliza, tornando-se, assim, um espaço criativo, conforme propõem Carneiro, Leite e Malpique (1983, p.18). As propostas de ocupação dos espaços contidas nas oficinas podem engendrar práticas diferenciadas das habitualmente desenvolvidas na escola e, se a elas forem articuladas as qualidades sensíveis que a arte convoca, podem vir a modificar o modo como esse professor vive o seu próprio espaço (como a organização de sua própria sala de aula, já que normalmente cabe a ele reorganizá-la conforme o seu planejamento diário, propondo cadeiras juntas de dois a dois, ou em círculo, entre outras possibilidades).

As oficinas foram de três horas de duração e, após a leitura de suas ementas e a escuta ao depoimento da professora, tenho como hipótese que elas instauram, no professor, a possibilidade de viver em grupo experiências sensíveis intercaladas às experiências programáticas vividas no cotidiano da escola. São elas então fraturas ou descontinuidades em relação ao vivido ou praticado no contexto escolar? Considerando que o cotidiano escolar, ele mesmo, contem as suas descontinuidades, supõe-se que elas sejam diferenciadas das que o professor experimenta nas oficinas em Serralves. Ali há que vivê-las em conjunto!

Se a escola se organiza pela programação, as interações que lá ocorrem obedecem às finalidades de uso deste contexto, e a quebra dessa programação gera uma retomada ao programático. Nesse regime de interação e de sentido ${ }^{19}$, há uma adaptação de um sujeito a outro (aluno a professor, professor a professor, diretor a professor, aluno a aluno, alunos e professores ao espaço da sala). Portanto, numa interação de ordem programática, para que se obtenham seus fins, é necessário que um sujeito se apoie em certas determinações preexistentes, estáveis e conhecidas do comportamento do outro.

O que as propostas das oficinas provocam para os seus participantes é um estar junto para viverem outras experiências. Pode-se supor então, que se constituem a partir de um outro modo de atuar que não tem relação com o programático. A esse outro modo de interação em que há uma dinâmica própria dos sujeitos, em que a interação emerge dela mesma, da co-presença sensível dos actantes ${ }^{20}$, Landowski (2009) chama ajuste. Uma interação que se dá face a face, corpo a corpo, em que não há uma adaptação de um sujeito a outro como na programação. É um fazer junto, de dois a dois (ou mais companheiros), num movimento em que cada um sente o sentir do outro (ou dos outros) em uma relação

\footnotetext{
${ }^{19}$ Consultar Landowski (2009).

${ }^{20}$ Actante é uma unidade sintáxica formal que designa o que ou quem realiza ou sofre o ato e participa de um processo.
} 
direta, corpo a corpo reunidos pelo contágio das emoções, dos ritmos da hexis ${ }^{21}$, ou seja, do modo próprio de cada sujeito estar no mundo. Está nessa capacidade de sentir-se reciprocamente o que Landowski chama de competência estésica. A interação não se baseia em um fazer-fazer, nem em um fazer-crer (próprio das estratégias da argumentação), mas em fazer sentir. Ocorre antes pelo contágio de sensibilidades do que pela persuasão entre inteligências.

Portanto, consideramos que as relações intersubjetivas propostas pelos enunciadores das oficinas e a temática que toma o corpo como matéria de seu fazer em um espaço sinestesicamente provado, aproximam os seus participantes/professores da arte contemporânea exposta em Serralves, sem, entretanto, empregar mecanismos que não sejam os da própria arte. A arte contemporânea, mesmo em sua diversidade, impõe outros modos de relação para quem com ela está disposto a interagir, como o envolvimento a partir do toque, da participação efetiva nela, experimentando-a corpo a corpo, experiências interativas que podem ser vividas na dinâmica que os enunciadores das oficinas promoveram aos participantes/professores.

Compreendo que assumir como ponto de partida a experiência dos artistas é considerar o caráter efêmero e experimental da produção artística e, conforme argumentam a coordenadora e a consultora do SE de Serralves sobre as estratégias que os artistas utilizam para convocar o público a interagir com as suas produções, é implicar o público em "[...] uma atitude activa, contrária à que caracteriza habitualmente o confronto com algo face ao qual este não possui referências" (LEITE e VICTORINO, Ib.dib, p. 27).

\section{II.3. Como professores e alunos participam na escola e da exposição.}

Se Serralves provoca, com a proposição do que chamaremos aqui de tema ampliado de Lugares Imaginários-Utopia, e propõe modos de aproximação e de estudo a partir das ações: seminário, oficinas e as visitas que, enriquecidas com informações, experiências e conhecimentos, cumprem o papel de apontar subsídios para que o professor crie o seu projeto, são os desejos e as motivações oriundas do contexto escolar que vão influenciar essa escolha que, coerente com a metodologia Trabalho de Projetos, é construída pelos professores e alunos.

As duas professoras com quem conversei optaram por projetos em cujos processos de ação interinstitucional entre Serralves e a escola diferenciaram-se bastante. Isso

\footnotetext{
${ }^{21}$ Sobre a noção de hexis, tomada de forma bastante livre dos trabalhos de Pierre Bourdieu (Bourdieu,1979), veja-se Landowski, 2004, p. 175-176.
} 
demonstra a autonomia do professor nessa metodologia de Trabalho de Projectos escolhida pelo SE de Serralves.

Entretanto, antes de escrever sobre os projetos das duas professoras, é preciso explicar a estrutura proposta pelo SE de Serralves para conciliar a entrega dos trabalhos produzidos nas escolas e a exposição final em Serralves.

As atividades são programadas num fazer-fazer ao outro e em estratégias de deverfazer, conforme consta no texto disponibilizado no ano 2012/2013 no sitio do SE:

O Serviço Educativo fornece a cada turma inscrita um pano branco, de grandes dimensões como campo de trabalho. Sublinha-se que este será o suporte para a concretização da produção final, que deverá ser exposto num lugar dentro ou fora da escola. Fornecerá também a etiqueta para ser pendurada num dos cantos do pano e um DVD para gravação das fotografias, vídeo e textos. Este ano será ainda disponibilizado o acesso a uma plataforma de partilha virtual, schools.com.serralves-informações, a disponibilizar brevemente.

O dever-fazer está explícito em cada etapa a ser cumprida por cada turma, e o SE de Serralves não apenas indica o fornecimento do suporte e dos materiais para filmagem e fotografia, como fornece os meios para cumprimento do programa estabelecido. Esta ação programática é a garantia de um mesmo tratamento a todos os participantes, principalmente quando se trata de um número extenso de trabalhos produzidos.

Na publicação Serralves: Projetos com Escolas (2008, p.141), encontro a primeira referência sobre o fornecimento do material de suporte para a realização dos trabalhos pelos alunos na escola. O tema foi Colecções Imprevistas e o ano de 2004/2005. A consultora reconhece que a indicação e fornecimento do suporte, ocasionaram críticas de limitação e de direcionamentos por parcela dos professores participantes do projeto, entretanto a nova postura foi assumida pelo SE de Serralves que compreendeu essa como possibilidade de expor um material tão extenso e diversificado.

Compreendo que, na metodologia de Trabalho de Projectos, é o enunciador, nesse caso Serralves, que, ao assumir o seu papel, encaminha aos demais os desafios que poderão enfrentar: o de resolver como uma temática pode ser tratada na escola e de apresentar trabalhos sobre ela em determinado suporte e dimensão. A cada etapa, o que se constrói são negociações como as realizadas entre Serralves e os professores, e estes, ao aceitarem o desafio, assumem essa responsabilidade diante da escola, dos pais e dos alunos. É um programa que se repete anualmente. O negociador nessa metodologia ${ }^{22}$, é

\footnotetext{
${ }^{22}$ Consultar Haité (1990).
} 
aquele que ao invés de impor a sua posição por meio de processos autoritários, explica os fios da meada, negocia as regras do jogo, incluindo-se no grupo.

Se esta é a conduta do SE de Serralves ela é condizente com a metodologia que afirma ser a que fundamenta os seus projetos educativos. É dessa maneira que, como afirmamos anteriormente, são firmados os contratos intersubjetivos, entre professores que realizam a mediação interinstitucional escola e museu.

Após a apresentação dessa etapa do projeto, que está sob a responsabilidade do SE de Serralves, vamos descrever as etapas subsequentes, que ocorrem nas escolas sob a coordenação dos professores.

A professora 1 leciona numa escola básica e secundária localizada na cidade do Porto. É uma escola que, desde 1959, ocupa o mesmo edifício em uma freguesia considerada como das mais populosas da cidade do Porto e de diversidade socioeconômica, pois atende desde a alunos oriundos de bairros camarários, até a outros de classe médiaalta, conforme aponta Gonçalves (2009, p. 13).

Nessa escola, seis professores participaram do projeto com Serralves, e o número de turmas envolvidas foi de aproximadamente vinte. Por contar com essa extensa participação, a escola, em parceria com Serralves, promoveu uma palestra com a profa. Fátima Vieira, da Faculdade de Letras da Universidade do Porto, com o tema Utopia e possibilitou a participação dos alunos e professores. Esta ação é uma marca discursiva de comprometimento dessa instituição com Serralves.

Entre estas vinte turmas, as quatro do $7^{\circ}$ ano, que corresponde ao $3^{\circ}$ ciclo do básico, escolheram um tema único para o desenvolvimento de seus projetos: "Cidades Utópicas". No texto que acompanha o cartaz de tamanho A2, em que está a fotografia do trabalho produzido e entregue ao SE de Serralves, os alunos, ao descreverem o processo de trabalho realizado na escola, citam: "Desde o início, a ideia era a construção de um mapa. Como seria construir uma cidade com as imagens de coisas que gostamos?"

Assim, cada turma construiu a sua cidade desenhada no suporte de tecido, com materiais e composições muitos distintas uma das outras, mas com um ponto em comum: as composições ocupam todo o suporte em um desenho único, o que nos leva a supor que foi uma construção conjunta compositiva da turma e não a junção de vários desenhos individuais no suporte.

$\mathrm{Na}$ totalidade dos trabalhos expostos em Serralves, as soluções figurativas e plásticas são tão singulares como os materiais utilizados pelos alunos para realizá-las, tais como: espelhos, contas, linhas, botões, tecidos, tintas, entre outros. Os trabalhos das turmas 
do $7^{\circ}$ ano utilizam as canetas hidrográficas, tintas e outros materiais de desenho e pintura em seus mapas.

Após a finalização e junto às demais turmas, "As cidades Utópicas" foram expostas primeiramente no átrio da escola e depois em um espaço exterior a ela, o que possibilitou a todos que ali circulam, estudam e trabalham, assim como à família e à comunidade em geral, conhecerem os trabalhos realizados.

A escola na qual a professora 2 leciona pertence a um Agrupamento com outras cinco escolas e se localiza no Concelho de Vila Nova de Gaia. Nela, a professora integrou o projeto de Serralves a um projeto de investigação que realiza no Curso Doutoral em Educação Artística da Universidade do Porto. O objetivo foi o de gerar nos alunos aprendizagens relativas ao artístico, especificamente à arte contemporânea, a partir das proximidades propiciadas tanto por Serralves, como por uma outra instituição promotora, a Casa da Imagem, bem como pelos próprios artistas no espaço escolar. Assim, como está previsto no projeto da professora, um artista do SE do Museu de Arte Contemporânea de Serralves, realizou na escola um projeto-oficina com um grupo de alunos nas aulas de Educação Visual e de Educação Tecnológica, do $2^{\circ}$ ciclo do ensino básico. Essa ação, assim como na outra escola, constitui uma marca da parceria interinstitucional que o projeto da professora realiza.

Entretanto, como esse projeto escolar possui uma duração maior que o Projectos com Escolas engloba, mas como a professora e os alunos demonstraram interesse em também participar e realizar o trabalho no suporte enviado por Serralves, a solução encontrada foi a de integrar a família dos alunos a esse processo de trabalho com projeto. Definida, então, pelo grupo de alunos, a temática, o suporte circulou e foi apropriado por eles e suas famílias. Construída por tantos, essa cidade é plataforma de visibilidade que integra a escola e a família. Laços a serem expostos em Serralves.

\section{II.5.A exposição como presentificação da escola, professores e alunos em Serralves.}

Com uma agenda que abrange desde o mês de maio ao final de setembro, a exposição é visitada tanto pelos habituais visitantes do museu, como pelas crianças e jovens participantes do projeto, que levam as suas famílias para conhecer o museu e a sala expositiva em que estão os seus trabalhos. 
A exposição que ali se apresenta possui uma concepção de montagem e de produção comparável as que estão expostas nas demais dependências de Serralves. Está incluído aí um folheto que, tal qual um catálogo, em suas oito páginas, informa a data da exposição, assim como, em seu interior, explica o funcionamento do Projetos, as ações que o envolvem, apresenta cada uma das escolas e/ou associações educativas participantes, bem como os respectivos professores e finaliza, na contracapa, com as informações dos artistas, monitores, estagiários envolvidos, assim como as equipes responsáveis pela concepção, montagem e produção.

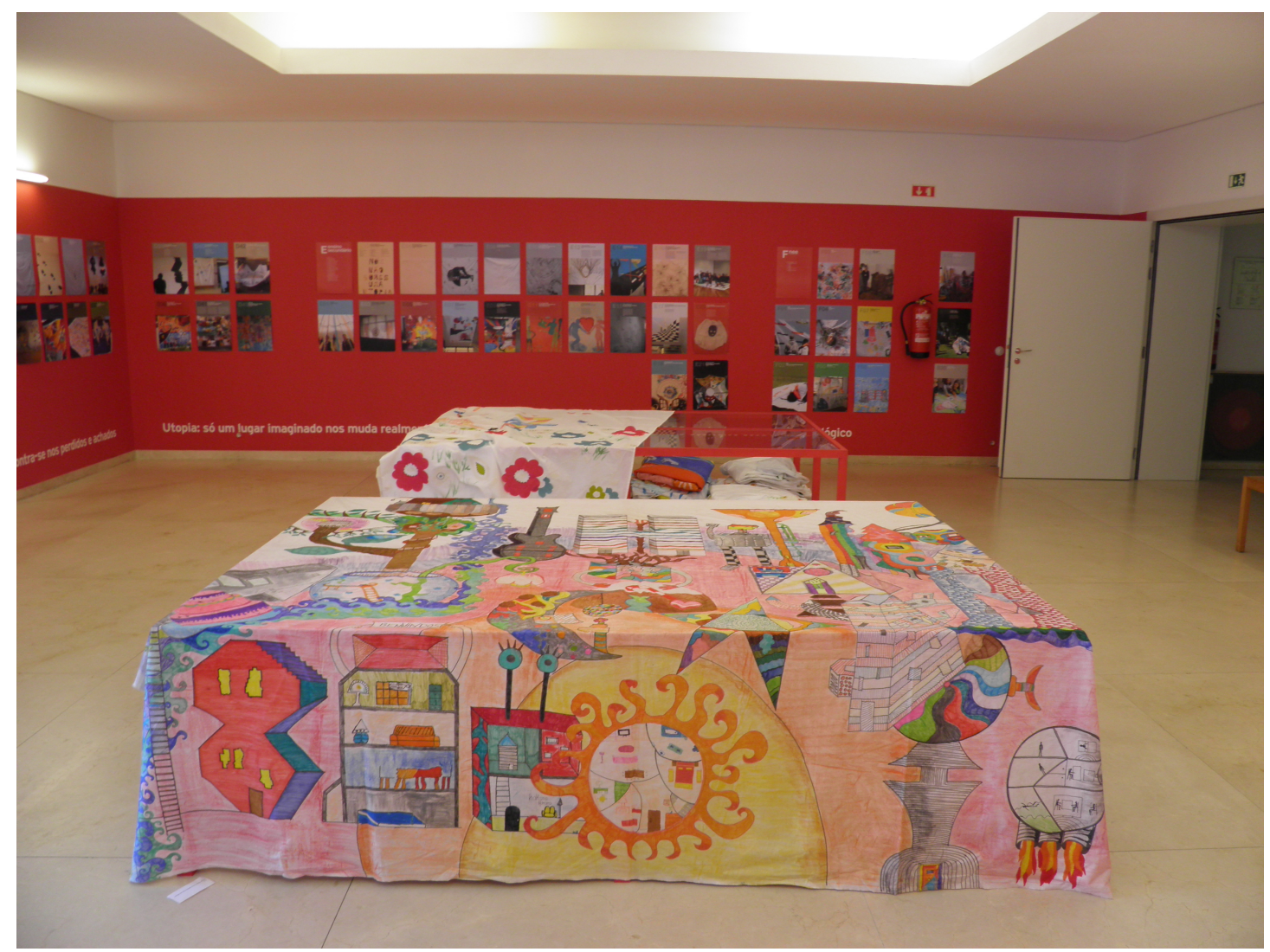

Fig.1.Sala de exposição no MAC de Serralves. Foto de Anaise Perrone

O SE de Serralves, como nos explica a consultora, recebe os trabalhos enviados pelas turmas participantes de cada escola e os expõe sem que haja uma seleção valorativa deles. Ou seja, todos os trabalhos que são enviados são expostos com as mesmas condições estabelecidas previamente.

$\mathrm{Na}$ exposição, essas informações são disponibilizadas ao visitante do seguinte modo: os trabalhos mesmos, no caso dos lençóis, eles ficam dobrados e dispostos em duas 
grandes estantes quadrangulares localizadas no centro da sala expositiva; ao redor dela são expostos, numa disposição de leitura linear, ou seja, dos primeiros ciclos da escola básica até o secundário, em formato $\mathrm{A} 2$, as fotos e os cartazes dos trabalhos com indicação das respectivas turmas (em alguns está presente o texto que justifica a escolha temática da turma). E, ao final da sala expositiva, há um grande painel com todos os participantes por escola e/ou associações e organizações educativas e seus respectivos professores. Ao lado e na frente dessa parede, estão disponibilizados três computadores/monitores onde é possível ao visitante assistir a todos os vídeos enviados e conhecer os alunos participantes.

A exposição possibilita essa interação com os trabalhos e a conhecer os seus participantes. Ela é, na opinião de Elvira, uma oportunidade avaliativa do projeto, não somente para o SE de Serralves, mas para os professores e alunos.

\section{IV-Projeto com Escolas: uma aproximação entre a Arte Contemporânea e as escolas.}

A leitura dos materiais produzidos por Serralves e o contato com os enunciadores e destinatários nos possibilitou conhecer e compreender uma parcela das ações realizadas pelo SE de Serralves em seu projeto anual com as escolas. Essas ações tecidas no meio social envolvem sujeitos que, ao compartilharem os mesmos valores, transformam o contexto em que atuam com práticas significantes (verbais, gestuais, espaciais, plásticas). As que nos foi possível conhecer foram aquelas manifestadas discursivamente pelos protagonistas, nas conversas que tivemos, e as presentes nos trabalhos plásticos e nos audiovisuais expostos em Serralves ${ }^{23}$. Para pontuar o que a análise nos permitiu construir ao longo deste artigo, apontarei, em tópicos, retomando como eixo, as questões motivadoras da investigação e como os sujeitos envolvidos, ao compartilharem diversas ações, interagem, além das modalidades convocadas no processo. Contudo, como em cada ação (seminários, oficinas, visitas), os sujeitos envolvidos ocupam posições distintas, procurei, a partir dos regimes de interação e de sentido em que elas estão inscritas, a saber, o de programação, de estratégia ou de persuasão e de ajuste, distribuí-las nesse quadro, para que possamos visualizar a reversibilidade dos papéis, das competências e da inserção dos sujeitos nas ações que, consideradas em sua totalidade, englobam.

\footnotetext{
${ }^{23}$ Ao considerar os limites dessa investigação, deixamos os produtos artísticos expostos para outra oportunidade, pois depende também da cessão, por parte de Serralves, das imagens dos trabalhos produzidos a análise plástica dos Lugares Imaginários e Utopias discursivizados pelas crianças e jovens participantes desse projeto.
} 
Propõe-se uma leitura que começa da esquerda para a direita, e que tem o SE de Serralves como enunciador e protagonista das ações. Entretanto, tenho as minhas dúvidas sobre a rigidez desse papel, pois, dada a longevidade do projeto, ele pode ter sido trocado, ou seja, embora ainda caiba ao SE de Serralves a escolha da temática anual e da oferta das ações que a integram, as escolas participantes e seus professores já consideram, em seus planejamentos, essa participação. Elas, então, são também protagonistas dessa ação que mobiliza o SE para, a cada ano, promover e atualizar o Projecto com Escolas.

Quadro 1

\begin{tabular}{|c|c|c|c|c|}
\hline \multicolumn{5}{|c|}{ Projetos com Escolas } \\
\hline \multirow{2}{*}{\multicolumn{2}{|c|}{$\begin{array}{c}\text { SE de Serralves } \\
\text { Projeto e suas ações } \\
\text { Querer, poder, saber (fazer). }\end{array}$}} & \multicolumn{2}{|c|}{ Escolas } & \multirow{2}{*}{$\begin{array}{l}\text { Serralves/ } \\
\text { escolas/ } \\
\text { Famílias/ } \\
\text { Comunidade }\end{array}$} \\
\hline & & Professores & Alunos & \\
\hline $\begin{array}{l}\text { Ações } \\
\text { programáticas } \\
\text { (fazer-fazer) }\end{array}$ & Os trabalhos & $\begin{array}{l}\text { Poder, querer, } \\
\text { Saber (fazer). }\end{array}$ & $\begin{array}{l}\text { Poder, } \\
\text { querer, } \\
\text { Saber, } \\
\text { Dever(fazer). }\end{array}$ & \multirow[t]{3}{*}{$\begin{array}{l}\text { trabalhos, } \\
\text { audiovisuais, } \\
\text { textos }\end{array}$} \\
\hline $\begin{array}{l}\text { Estratégias } \\
\text { Persuasão } \\
\text { (fazer-crer) }\end{array}$ & $\begin{array}{l}\text { Seminários, } \\
\text { Visitas } \\
\text { Oficinas } \\
\text { trabalhos }\end{array}$ & $\begin{array}{l}\text { Fazer-interpretativo, } \\
\text { Fazer-persu.(alunos) } \\
\text { Poder-fazer } \\
\text { Querer-fazer }\end{array}$ & $\begin{array}{l}\text { Fazer- } \\
\text { interpretativo } \\
\text { Poder-fazer } \\
\text { Querer-fazer }\end{array}$ & \\
\hline $\begin{array}{l}\text { Ações de ajuste } \\
\text { (fazer-sentir) }\end{array}$ & $\begin{array}{l}\text { Oficinas, } \\
\text { Visitas, } \\
\text { Trabalhos. }\end{array}$ & Poder-sentir & Poder-sentir & \\
\hline
\end{tabular}

Nessa gramática que a sintaxe narrativa permite visualizar, não são os fazeres operadores que transformam e motivam as ações, mas a maneira como um destinador exerce a sua capacidade de fazer os demais agirem e, nesse ato, fazer agir a si mesmo. De um fazer-fazer próprio do regime da programação à persuasão do fazer-crer ao outro que, em seu fazer-interpretativo aceita, ou rejeita o que se lhe propõe, até o fazer-sentir próprio do regime de ajuste, temos modos de agir actanciais próprios dos modos de presença dos sujeitos no mundo. Se o primeiro está fundado numa lógica da regularidade de comportamentos tanto de ordem física, como por condições socioculturais, o regime de estratégia ocorre em termos de intersubjetividade e de interioridade, ou seja, o principio é o da intencionalidade. A persuasão requer sujeitos que compartilhem valores, pois nela um age sobre o outro, um deseja que o outro deseje. Ao contrário, no ajuste, a lógica é a da sensibilidade e, nela, um sujeito busca fazer junto e sentir junto. Portanto, o sentido está na relação que é estabelecida entre os actantes e nas transformações que neles se operam tão somente por sua co-presença sensível (Landowski, 2009). Portanto, não há, aqui, comportamentos previsíveis. 
Explicada a base metodológica visualizada no Quadro 1, pode-se compreender como, em cada etapa do Projetos com Escolas, as relações entre os sujeitos e entre as instituições que ocupam se reposicionam e, se há um fazer-persuasivo do SE de Serralves e um fazer-interpretativo do professor, na outra etapa, ou seja, na escola, o fazer-persuasivo do professor é que vai motivar os alunos a participar e a querer e poder fazer os seus trabalhos, e assim sucessivamente, num movimento em que um motiva o outro, seja por intencionalidades, seja por sensibilidades.

As relações estabelecidas, então, não são somente verticalizadas (como as programáticas), são também horizontalizadas e mais intersubjetivas que interinstitucionais. Pode-se afirmar que a intencionalidade do Trabalho de Projectos seja justamente esta, a de, em suas ações e ao incluir diversos atores promover a passagem do desejo à intenção e da intenção ao ato.

Se é a partir de Trabalho de Projetos que o SE de Serralves organiza-se e estrutura-se, pode-se afirmar que é com essa metodologia que a instituição Serralves integra a Arte Contemporânea com a educação e a sociedade. Portanto, conforme a tipologia de Darras (2009), as relações entre arte e cultura construídas ali pertencem aos sistemas dialógicos, pois mantêm autonomia tanto institucional (museu e escola), como entre os sujeitos envolvidos (SE de Serralves, professores e alunos).

A pesquisadora Carmen Lidón Beltrán (2005, p. 365), ao apontar, em sua investigação, o lugar do Museu de Arte na cultura contemporânea como gerador de conhecimento diversificado, cita como exemplo o projeto Habitares desenvolvido por Serralves e seu objetivo de implicar, em suas ações, distintos públicos, em diversos momentos e envolvê-los em experiências variadas, culminando na exposição dos trabalhos no museu. Trata-se do Projectos com Escolas e, no que ela pôde acompanhar, destaca como, a partir de projetos como este, a educação da arte em espaço de Arte Contemporânea pode promover ${ }^{24}$ :

- ensinar a aprender fazendo (Dewey);

- questionar e dialogar (Freire e Barbosa);

- promover atitudes socializantes ao atender a diferentes grupos (multiculturalidade);

- utilizar as novas tecnologias;

- abranger e se apropriar de diversos suportes e linguagens artísticas (música, dança, teatro, artes visuais, performances, entre outras);

\footnotetext{
${ }^{24}$ Às práticas apontadas pela pesquisadora, acrescentei outras e as coloquei em itálico.
} 
Aos apontados por Beltrán acrescento outros mais que a análise permitiu apreender, a partir das ações enunciadas e das conversas realizadas:

- problematizar o cotidiano e a vida integrando-os com a Arte Contemporânea;

- integrar e promover a interdisciplinaridade;

- $\quad$ promover a autonomia dos envolvidos nas ações (professores e alunos);

- deslocar os espaços de aprendizagem para o exterior (fora da sala de aula);

- integrar Arte Contemporânea, Ciência e Ambiente.

O Projeto com Escolas constitui-se e ao mesmo tempo configura-se como um projeto educativo que, ao integrar o museu com as escolas, propicia às duas instituições atualizarem-se anualmente e, nesse processo e com as experiências advindas dele, renovarem-se constantemente. Para concluir, aponto um exemplo dessa renovação, a "quebra" de uma das mais emblemáticas noções associadas ao museu, aquela que o vê como espaço reverencial. Não é o que ocorre quando, em uma de suas salas, o que está exposto são os trabalhos realizados pelos alunos e seus professores? De público a expositores, o deslocamento provocado reposiciona e reorganiza os espaços e atores envolvidos e, nesse movimento, o sistema da arte busca energia em seu meio ambiente cultural e naquele ambiente, que é complementar a ele como espaço da educação. É assim que, para Darras (2009, p. 35), a arte se regenera.

\section{REFERÊNCIAS}

ANICO, Marta (2008). Museus e a Pós-Modernidade: discursos e performances em contextos museológicos locais. Universidade Técnica de Lisboa. Lisboa: Instituto Superior de Ciências Sociais e Políticas.

ARGAN,G.C. Arte e Crítica de Arte. Lisboa: Editorial Estampa, 1993

BARBIER,R. Pesquisa-Ação na Instituição Educativa. Rio de Janeiro. Jorge Zahar Editora, 1985.

BARBOSA, A. "Mediação Cultural e Social". In: BARBOSA, A e COUTINHO, R.(orgs.). Arte educação como mediação cultural e social. São Paulo: Editora UNESP, 2009, p.13-22.

BELTRÁN, C.L. (2005). "Educación Artística y formación estética en Museus, Centros de Arte y Patrimônio". In: VIADEL, Ricardo (ed.) Investigación en Educación Artística: temas, métodos y técnicas de indagación sobre el aprendizaje y la ensenanza de las Artes y Culturas Visuales. Granada: Ed. Universidad de Granada, 2005, p.365/370.

BOURDIEU, P. La distinction. Paris: Minuit, 1979.

CARNEIRO, A, LEITE, E, MALPIQUE, M. O espaço pedagógico: 2 Corpo/Espaço/Comunicação. Porto. Edições Afrontamento, 1983. 
CORTESÃO, L. "Projecto, Interface de Expectativa e de Intervenção". In: LEITE, E; MALPIQUE, M e SANTOS, M. Trabalho de Projecto: 2. Leituras comentadas. Porto: Ed. Afrontamento, 1990, p. 81-89.

DARRAS, B. (2009). "As várias concepções da cultura e seus efeitos sobre os processos de mediação cultural”. In: BARBOSA, A e COUTINHO, R.(org). Arte educação como mediação cultural e social. São Paulo: Editora UNESP, 2009, p. 23-52. Trad. Silvana Bernardes Rosa et al.

DEWEY, J. Experiénce et education. Paris: A. Collin. P. 1968, p. 117-123.

GONÇALVES, D. A Escola Pública e a Arte Pública: a ilusão do acesso para todos. (Mestrado em Ensino de Artes Visuais). Faculdade de Psicologia e de Ciências da Educação da Universidade do Porto e Faculdade de Belas Artes da Universidade do Porto, 2009.

GREIMAS, A. Sémiotique et sciences sociales. Paris: Seuil, 1976.

GREIMAS, A. et al. Práticas e Linguagens Gestuais. Lisboa: Ed. Vega, 1980

GRINSPUM, D. Educação para o Patrimônio: Museu e escola - Responsabilidade compartilhada na formação de públicos. São Paulo: s.n. Tese de doutorado - Faculdade de Educação/Universidade de São Paulo, 2000.

LANDOWSKI, E. Passions sans nom. Paris: P.U.F., 2004.

. Interacciones arriesgadas. Trad. de Blanco, Desiderio. Lima: Universidad de Lima, Fondo Editorial, 2009.

LEITE, E; MALPIQUE, M. e SANTOS, M. Trabalho de Projecto: 1. Aprender por Projectos centrados em problemas. Porto: Ed. Afrontamento, 2001.

Trabalho de Projecto: 2. Leituras comentadas. Porto: Ed. Afrontamento, 2001.

LEITE, E. \& VICTORINO, S. Serralves: Projectos com Escolas 2002-2007. Porto: Fundação Serralves, 2008.

SEMEDO, Alice; FERREIRA (2011). "Museus e Museologia: desafios para a construção de territórios colaborativos" In Revista da Faculdade de Letras da Universidade do Porto, Vol. XXI, pág. 97-119.

STOER, Stephen (1982). Educação, Estado e Desenvolvimento em Portugal. Lisboa: Livros Horizonte.

Fundação Serralves; Disponível em: http://www.serralves.pt/pt/fundacao/a-fundacao/eixosestrategicos/.Acesso em: 4 de jul. 2013.

Projeto com escolas; Disponível em: http://1213.projetoescolas.serralves.pt/pt/ Acesso em: 05 ago. 2013.

Oferta de oficinas Serralves para inscrição de alunos. Disponível em:

http://1213.projetoescolas.serralves.pt/fotos/editor2/fichadeinscricaoalunos.pdf Acesso em: 05 ago. 2013. 
Oferta de oficinas Serralves para inscrição dos professores. Disponível em: http://1213.projetoescolas.serralves.pt/fotos/editor2/fichadeinscricaoprofessores.pdf Acesso em: 05/08/2013.

Programas das oficinas de Serralves 2012/2013. Disponível em: http://1213.projetoescolas.serralves.pt/fotos/editor2/programadeoficinas.pdf Acesso em: 05 ago. 2013.

História de Serralves Disponível em: http://www.serralves.pt/pt/parque/historia/. Acesso em: 09 ago. 2013. 